\title{
THE METABOLISM OF l-TYROSINE IN INFANTILE SCURVY ${ }^{1}$
}

\author{
By JEFFREY E. MORRIS,2 ELEANOR R. HARPUR, AND ALTON GOLDBLOOM \\ (From the Departments of Biochemistry and Medicine, The Children's Memorial Hospital, and \\ the Department of Pediatrics, McGill University, Montreal, Canada)
}

(Received for publication September 7, 1949)

Attention has been drawn by Levine, Marples, and Gordon (1) to the relationship between ascorbic acid and the urinary excretion of aromatic amino acid intermediates by the normal premature male infant, both during periods of high protein intake and supplemental tyrosine and phenylalanine ingestion. To our knowledge, no reports have been forthcoming of similar studies with older, ascorbic acid depleted subjects. ${ }^{3}$ This communication is concerned with the metabolism of $l$-tyrosine in infantile scurvy. Observations have been made on the urinary excretion products, the serum content of both hydroxyphenyl compounds and amino acid nitrogen.

Sealock and his co-workers (2) have demonstrated that the oral administration of $l$-tyrosine to scorbutic guinea pigs results in the urinary excretion of the amino acid and its two principal deaminated products, parahydroxyphenylpyruvic and parahydroxyphenyllactic acids. A proof that this metabolic disorder is primarily dependent upon the state of ascorbic acid depletion is afforded by the observation that the tyrosyluria (hydroxyphenyluria) is abolished when the vitamin is given orally or parenterally.

Certain liver extracts are capable of modifying an induced tyrosyluria $(1,3)$, and recently Woodruff and Darby $(4,5)$ have indicated that pteroylglutamic acid (PGA) exerts a similar effect in the depleted guinea pig maintained on a basal scorbutogenic diet with supplements of $l$-tyrosine. By the administration of PGA to normal premature infants, Govan and Gordon (6) in several instances observed a diminution in the tyrosyluria

\footnotetext{
1 Read in part at the Annual Meeting of the Canadian Society for the Study of Diseases of Children, Wellesley Island, N. Y., June 18, 1949.

2 Dickinson Research Fellow of the University of Manchester, Manchester, England.

${ }^{3}$ Recently a short report in the Proceedings of the 41st Annual Meeting of the American Society for Clinical Investigation (J. Clin. Invest., 1949, 28, 806) was made by W. F. Rogers, Jr., and F. Gardner, in which the effect of tyrosine in human scurvy was studied.
}

established by dietary cow's milk protein. Several in vitro studies on the respiration of liver preparations with tyrosine as a substrate (7-9) tend to confirm that ascorbic acid, PGA, and certain liver fractions are concerned with the complete metabolism of tyrosine.

The appearance of alkaptonuria during periods of high aromatic amino acid consumption has been noted in the albino rat (10) and in the scorbutic guinea pig (11), but the excretion of homogentisic acid by human subjects in a state of ascorbic acid depletion has not been reported.

The present investigation is concerned with the effect of ascorbic acid, PGA and vitamin B12, on the urinary and serum tyrosyl content of several infants with clinical and preclinical scurvy during supplemental $l$-tyrosine feedings.

\section{METHODS}

Urine specimens were collected under toluene and stored at $4^{\circ} \mathrm{C}$. Metaphosphoric acid was used in addition to toluene as a preservative when urinary ascorbic acid analyses were undertaken. Blood samples, when required, were obtained by internal jugular puncture approximately one and one-half hours after feeding. The sera were kept frozen until their amino acid nitrogen. and hydroxyphenyl content had been estimated. All colorimetric estimations were made with either a Coleman Junior spectrophotometer or an Evelyn photoelectric colorimeter.

\section{1) Total Urinary Tyrosyl (Hydroxyphenyl) Compounds}

These were estimated by the method of Folin and Ciocalteau as modified by Medes (12) and adapted to the spectrophotometer at a wavelength of $465 \mathrm{~m} \mu$.

\section{2) Urinary Tyrosine}

In the estimation by the method of Medes (12), the insoluble lead salts of deaminated intermediates are removed from the urine at $\mathrm{pH}$ 7.0. The estimation of "tyrosyl" in the supernatant fluid gives an approximate value for the urinary tyrosine.

\section{3) Urinary Tyrosine Intermediates}

This value was obtained by subtracting the tyrosine content from the total urinary tyrosyl compounds. That parahydroxyphenyllactic acid was a component of the 
TABLE I

Analysis of cases

\begin{tabular}{|c|c|c|c|c|c|c|c|c|c|c|}
\hline Case & Type & $\begin{array}{l}\text { Age in } \\
\text { months }\end{array}$ & $\begin{array}{c}\text { Kilos. } \\
\text { weight }\end{array}$ & $\begin{array}{l}\text { Serum } \\
\text { vit. C }\end{array}$ & $\begin{array}{l}\text { Urinary } \\
\text { vit. C }\end{array}$ & $\underset{\text { irritability }}{\text { Clinical }}$ & $\begin{array}{c}\text { Tender } \\
\text { limbs }\end{array}$ & $\underset{\text { beading }}{\text { C. } C .}$ & $\begin{array}{l}\text { Microscopic } \\
\text { haematuria }\end{array}$ & $\begin{array}{c}\text { X-ray } \\
\text { change }\end{array}$ \\
\hline $\begin{array}{c}\text { Case } 1 \\
\text { P. R. }\end{array}$ & Scurvy & 9 & 6.2 & $\begin{array}{c}\text { mgms.\% } \\
0\end{array}$ & $\begin{array}{c}\text { mgms.\% } \\
0.1\end{array}$ & + & + & + & + & + \\
\hline $\begin{array}{l}\text { Case } \\
\text { R. C. }\end{array}$ & Scurvy & 8 & 7.9 & 0 & 0.05 & + & + & + & + & + \\
\hline $\begin{array}{c}\text { Case } 3 \\
\text { R. R. }\end{array}$ & Prescurvy & 5 & 6.6 & 0 & 0.04 & + & 0 & + & 0 & 0 \\
\hline $\begin{array}{c}\text { Case } 4 \\
\text { M. S. }\end{array}$ & Prescurvy & 10 & 6.5 & 0.1 & 0.3 & + & 0 & + & 0 & 0 \\
\hline $\begin{array}{r}\text { Case } 5 \\
\text { P. P. }\end{array}$ & Scurvy & 7 & 8.7 & 0 & 0.1 & + & + & + & + & + \\
\hline $\begin{array}{r}\text { Case } 6 \\
\text { C. } R .\end{array}$ & Prescurvy & $7 \frac{1}{2}$ & 6.9 & 0 & 0.1 & + & 0 & + & 0 & 0 \\
\hline
\end{tabular}

tyrosine intermediates was demonstrated as follows. The lead salt was reduced with hydrogen sulphide followed by extraction with ether of the resulting free acid. Recrystallization, first from alcohol and finally from ether, yielded white needle-shaped crystals which melted sharply at $169^{\circ}-170^{\circ} \mathrm{C}$. The pyruvic acid derivative could not be isolated, presumably due to rapid polymerization.

4) Urinary Ascorbic Acid

Method of Evelyn, Malloy, and Rosen (13).

\section{5) Serum Ascorbic Acid}

Method of Mindlin and Butler (14).

\section{6) Serum Hydroxyphenyl Compounds}

This method utilizes the reaction of Gerngross, Voss, and Herfeld (15) which is specific for parahydroxyphenyl compounds which are neither substituted in both ortho positions nor have a single ortho methyl group.

\section{Reagents}

(i) $10 \%$ Trichloracetic acid solution

(ii) $1 \%$ solution of 1.2 nitroso-betanaphthol (Merck) in glacial acetic acid

(iii) $10 \%$ nitric acid

(iv) $2 \%$ sodium bisulphite solution

(v) $95 \%$ ethyl alcohol

\section{Methods}

One ml. of serum was mixed with $5 \mathrm{mls}$. of $10 \%$ trichloracetic acid and allowed to stand for 10 minutes. After centrifugation, $3 \mathrm{mls}$. of the protein-free supernatant were transferred to a $6 \times 3 \%$ " pyrex test-tube and a blank prepared in a second tube with $3 \mathrm{mls}$. of $10 \%$ trichloracetic acid.

One ml. of the $1 \%$ nitrosonaphthol reagent was added to $9 \mathrm{mls}$. of distilled water and $1 \mathrm{ml}$. of this dilute solution pipetted into each tube, followed by the addition of $1 \mathrm{ml}$. of $10 \%$ nitric acid. After mixing, the tubes were heated in a boiling water bath for five minutes and then cooled in ice water for a further five minutes. Following the addition of $1 \mathrm{ml}$. of $2 \%$ sodium bisulphite solution to each tube, the contents were transferred to a $10 \mathrm{ml}$. volumetric flask and made up to volume with washings of $95 \%$ ethyl alcohol.

The test solution was read immediately in the spectrophotometer against the blank at a wavelength of $450 \mathrm{~m} \mu$. Reference was made to a standard calibration curve prepared from a solution of $l$-tyrosine in $10 \%$ trichloracetic $(0.02 \mathrm{mgm} . / \mathrm{ml}$.) over a range of $0-0.06 \mathrm{mgm}$., each tube finally containing $3 \mathrm{mls}$. of $10 \%$ trichloracetic acid. A similar curve prepared from equimolar quantities of parahydroxyphenyllactic acid is identical with that obtained from $l$-tyrosine.

It was shown that non-aromatic amino acids do not interfere with this reaction (15).

\section{7) Serum Amino Acid Nitrogen}

The method of Krauel (16) was used with the following modifications. A 1:6 trichloracetic acid filtrate was prepared as described in the method above. The sodiumbetanaphthoquinone-disulphonate reagent (Eastman) was made up in $5 \%$ sodium borate solution. The reaction was allowed to proceed in a boiling water bath for 10 minutes and the tubes were then cooled in ice-water for five minutes. Transmission was estimated in the spectrophotometer at $475 \mathrm{~m} \mu$ and the amino nitrogen content of the serum derived from a standard calibration curve prepared with $l$-tyrosine. The addition of parahydroxyphenyllactic acid in the above method was found not to interfere with this reaction.

\section{CLINICAL MATERIAL}

The six male infants selected for this metabolic study were all under one year of age. All had a history of meagre ascorbic acid intake since birth and in each infant the serum and urinary ascorbic acid values were either 
extremely low or zero (Table I). Those designated as being scorbutic (Cases $1,2,5$ ) were clinically irritable, anorexic, and had tender extremities. All exhibited beading of the costochondral junctions, microscopic haematuria, and radiological evidence of scurvy in the long bones. The infants who were put into the category of "preclinical scurvy" had no demonstrable radiological changes or haematuria. They too were irritable and anorexic and had some degree of costochondral beading. After completion of the metabolic study, when the patients received ascorbic acid therapy, a marked clinical improvement was apparent in all. Radiological evidence of healing was observed in those who initially had bone lesions.

Tyrosine was given in a dosage of $1.0 \mathrm{gm}$. per kilo body weight per 24 hours, and incorporated in a day's formula which provided approximately 3.5 gms. of cow's milk protein per kilo daily. Vitamins A, D, and B complex were added.

\section{RESULTS}

When the milk formula was ingested without added tyrosine, the 24 hour urinary hydroxyphenyl excretion in no instance exceeded 70 mgms. expressed as equivalents of tyrosine. Serum amino acid nitrogen values at the beginning of each metabolic study were below 5.0 mgms. per
$100 \mathrm{mls}$. and the corresponding levels of serum tyrosyl did not exceed 6.0 mgms. per $100 \mathrm{mls}$.

Case 1. . P. R., 9 months. Diagnosis-scurvy

It can be seen from the urinary excretion chart (Figure 1) that the ingestion of $l$-tyrosine over periods 10 and 11 produced an hydroxyphenyluria comprising tyrosine and its two principal intermediates. Urine specimens were collected for 24 hour periods except during period 11 when separate 12 hourly collections were made. The urinary tyrosyl excretions depicted as representing 12 hour outputs were calculated in all periods except 11 by halving the 24 hour excretion values.

It is not clear whether an immediate tyrosyluria was evoked by the ingestion of the amino acid. Possibly the tyrosyluria which occurred during the second 12 hours of period 10 was of sufficient magnitude to give an average of approximately 500 mgms. for both 12 hourly periods. One can conclude, however, that the onset of the hydroxyphenyluria certainly occurred within the first 24

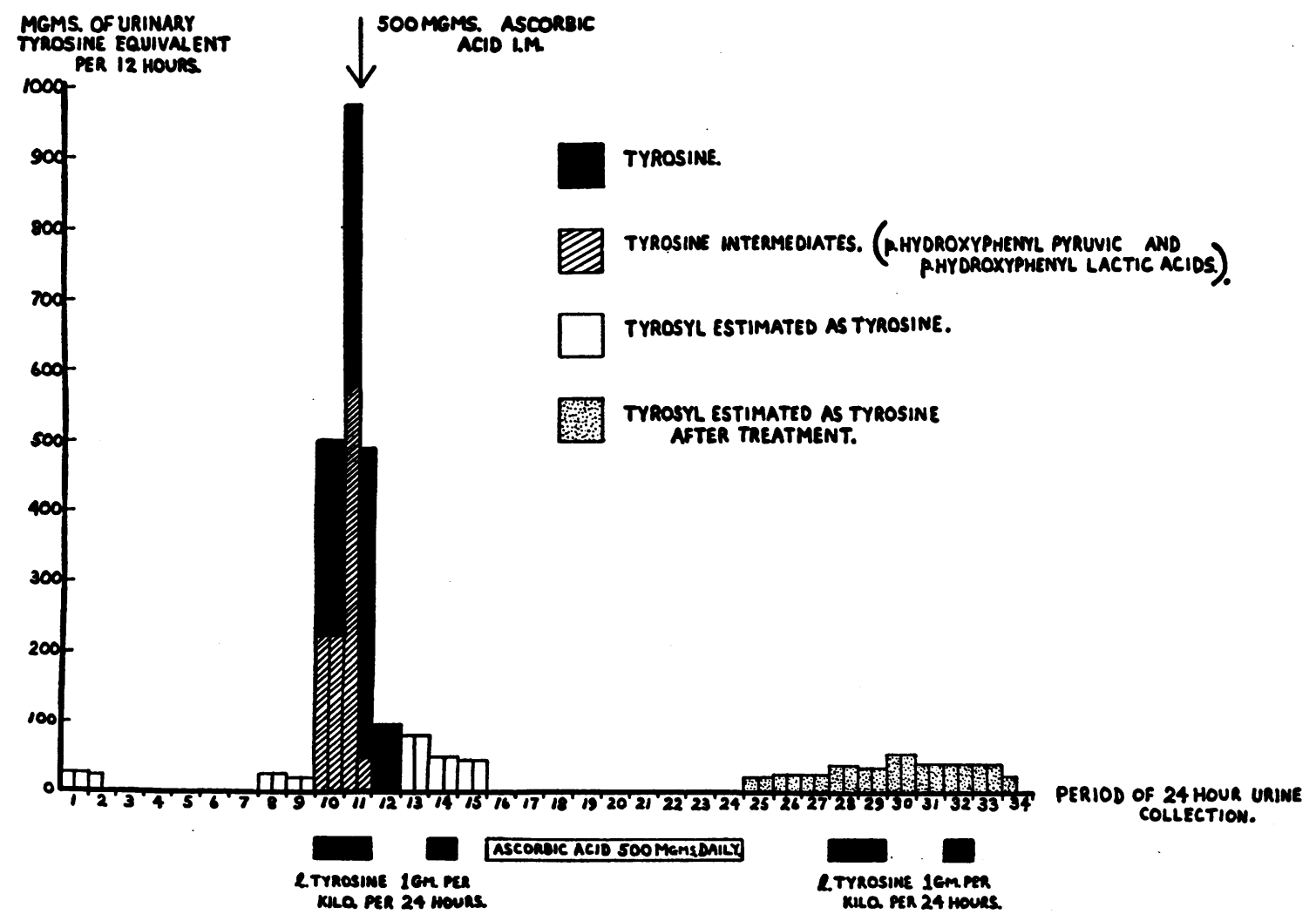

FIc. 1 
hours of tyrosine ingestion, and perhaps in the first 12 hours.

An injection of $500 \mathrm{mgms}$. of ascorbic acid at the midpoint of period 11 produced a diminution in the tyrosyluria, although tyrosine feeding continued throughout that period, and one would have expected a progressive increase in the hydroxyphenyluria. The initial action of ascorbic acid was associated with the disappearance of the intermediate products of tyrosine metabolism from the urine with subsequent disappearance of tyrosine itself.

An additional day of tyrosine consumption (period 14) failed to produce an increase in tyrosyl output. Furthermore, after nine days of ascorbic acid therapy consisting of daily oral supplements of 500 mgms., a repetition of the tyrosine feeding regime produced no significant increase above the normal basal urinary excretion of hydroxyphenyl compounds.

Case 2. R. C., 8 months. Diagnosis-scurvy

Ingestion of $l$-tyrosine was continued for three days (periods 8, 9 and 10, Figure 2). Urines were collected for 24 hour periods and the calcu- lated 12 hourly excretion values plotted, except for periods 9 and 10 when actual 12 hourly collections were made. Again the onset of tyrosyluria occurred within 24 hours and possibly during the first 12 hours after the addition of tyrosine to the formula. The excretion of tyrosine intermediates was progressive whereas the output of tyrosine remained relatively unchanged. At the height of the tyrosyluria, acid-soluble crystals with the configuration of $l$-tyrosine were observed in the urinary sediment.

The injection of $45 \mathrm{mgms}$. of PGA at the midpoint of period 9 failed to prevent the progressive hydroxyphenyluria while tyrosine was ingested. However, the administration of $500 \mathrm{mgms}$. of ascorbic acid intramuscularly caused an immediate diminution in the total urinary tyrosyl output and particularly in the excretion of metabolic intermediates. As in the previous infant, an additional day of tyrosine ingestion and a repetition of the tyrosine feeding regime after therapy with ascorbic acid, failed to evoke a tyrosyluric response.

It is apparent that PGA given as shown failed to have any immediate effect on the hydroxyphenyluria whereas ascorbic acid exerted a pronounced action.

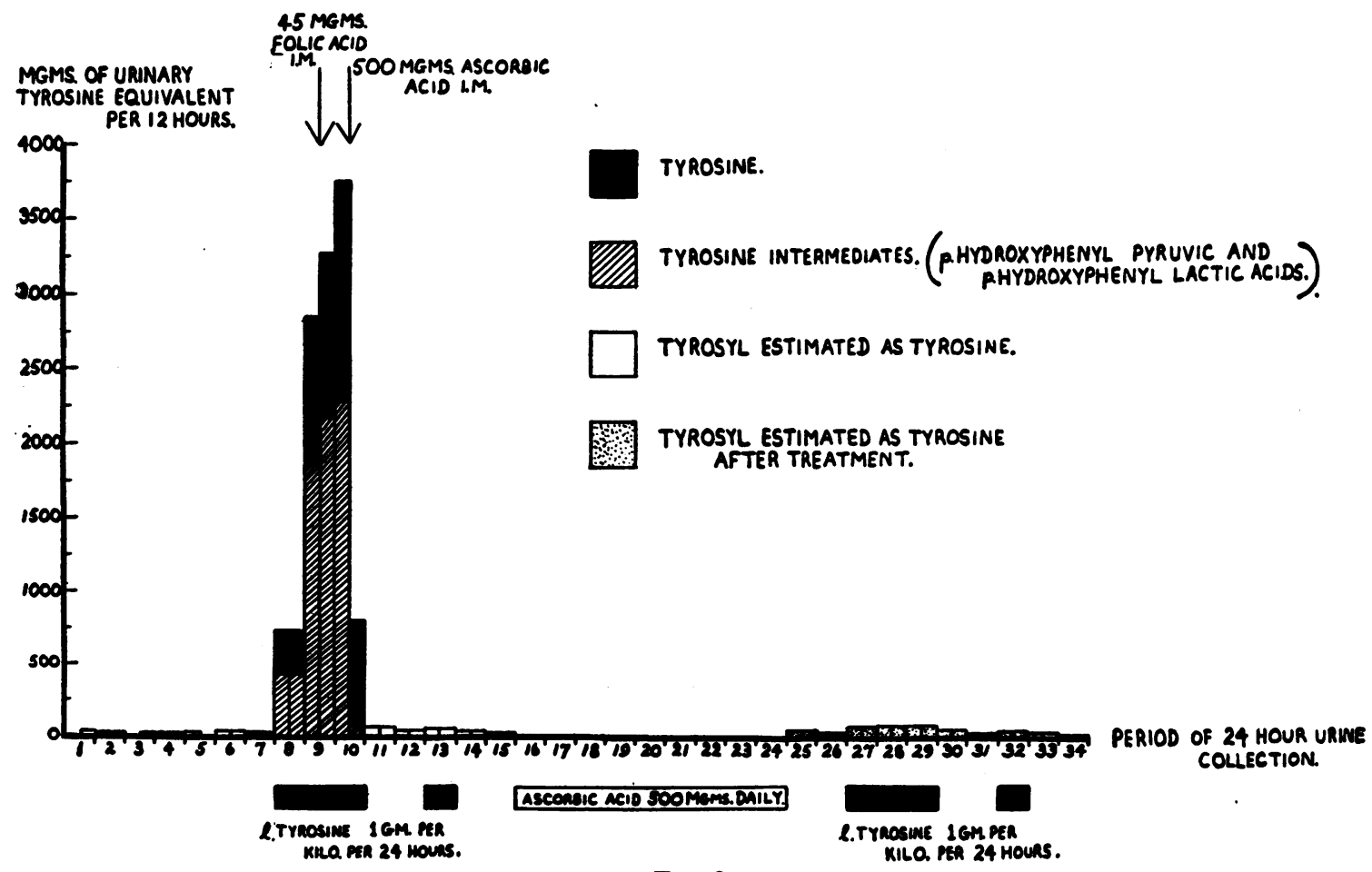

FIG. 2 

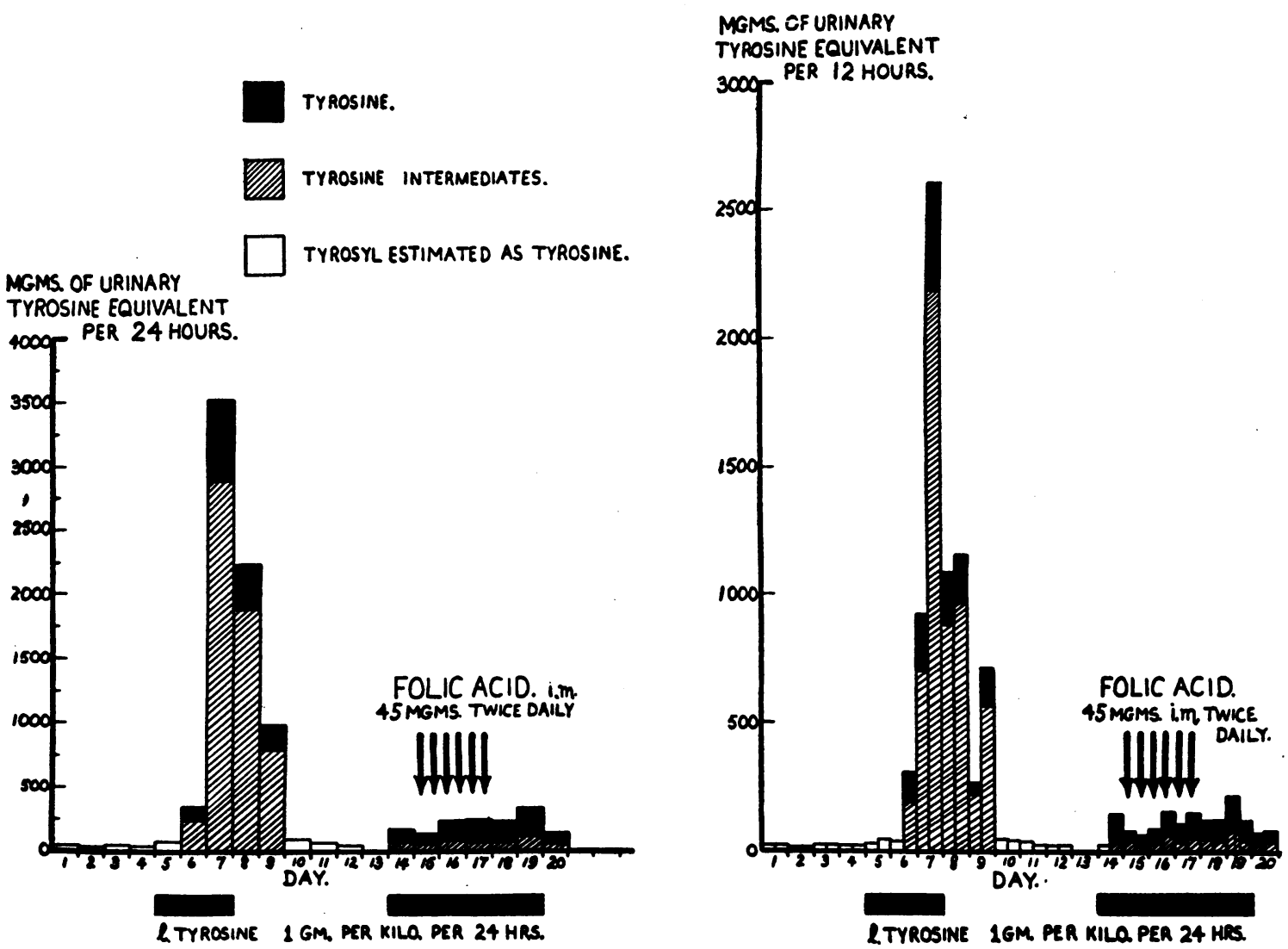

FIG. 3A

Case 3. R. R., 5 months. Diagnosis-preclinical scurvy

In this case PGA was administered concurrently with tyrosine supplements in a dosage of 45 mgms. intramuscularly twice daily during periods 15,16 and 17 . Urine collections were made at 12 hourly intervals and both 12 and 24 hourly excretion values are charted (Figure $3 \mathrm{~A}$ ). It was first shown that the infant would exhibit a tyrosyluria during the second 12 hours of period 6 after 36 hours of tyrosine feeding. Maximum hydroxyphenyluria developed during period 7 , again with the appearance of a crystalline substance in the urine. As in the previous case it is possible that these crystals, conforming to the shape of $l$ tyrosine, may have been those of the intermediate products of metabolism. No ascorbic acid was given and the tyrosyluria diminished gradually over the next few days and returned to normal values.

When tyrosine was again ingested beginning at period 14, tyrosyl compounds appeared in the urine after 12 hours. PGA, when given twice daily for three days in conjunction with tyrosine feeding, prevented any further increase in tyrosyluria. It is to be noted that during periods 18 and 19, when tyrosine consumption continued in the absence of PGA injection, no gross urinary excretion of tyrosine compounds was evident. Urines from periods 16 and 17 were observed to darken when they were alkalinized and allowed to stand overnight.

These results indicate that PGA given during a prolonged ingestion of the amino acid is capable of preventing the occurrence of tyrosyluria. Its effect extended for at least two days following the last injection. In addition, the observed darkening of the urine during the second period of tyrosine feeding suggests that homogentisic acid was excreted in spite of the apparently adequate utilization of $l$-tyrosine as judged by the urinary output studies.

Serum values of amino acid nitrogen and tyrosyl (Figure 3в) demonstrate that a parallel 


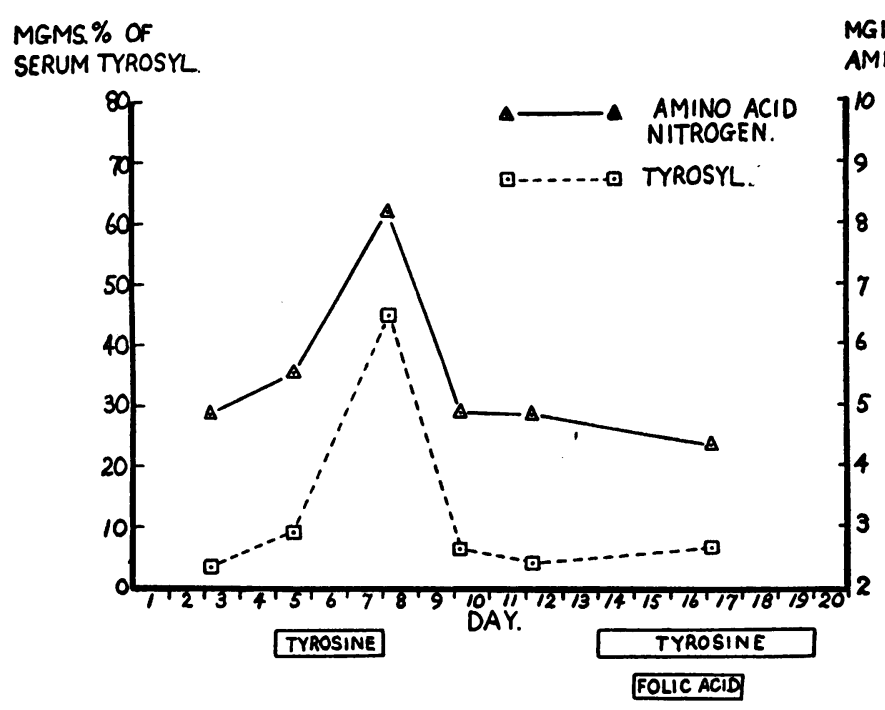

FIG. 3B

relationship existed between these two components and a peak in both values occurred when the tyrosyluria was at a maximum. When PGA was given concurrently with $l$-tyrosine no increase in either the serum amino nitrogen or tyrosyl content was apparent.

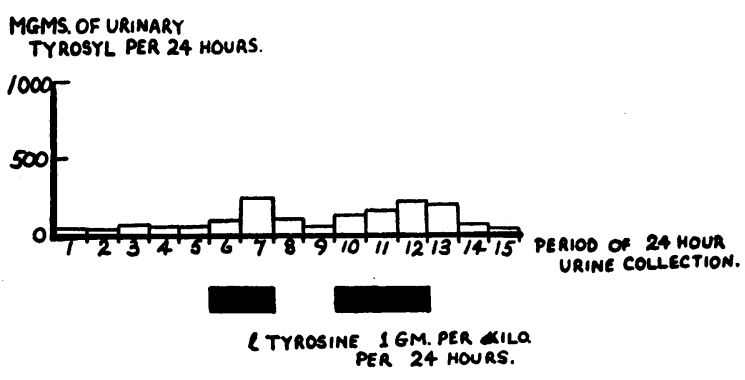

Fig. 4A
MGMS.\% OF SERUM AMINO ACID NITROGEN.

\section{Case 4. M. S., 10 months. Diagnosis-pre- clinical scurvy}

Tyrosine supplementation during periods 6,7 , 10, 11 and 12, as shown in Figure 4A, resulted in only a moderate tyrosyluria. At the end of the second course of amino acid consumption darkening of the urines was noticed.

Investigation of serum levels (Figure 4B) showed that amino acid nitrogen and tyrosyl fluctuated over a small range with the output of urinary tyrosyl. The final high value for serum amino acid nitrogen was presumably due to the presence of serum sulphadiazine which interferes with the estimation.

In this particular infant with preclinical scurvy, neither intense hydroxyphenyluria nor gross

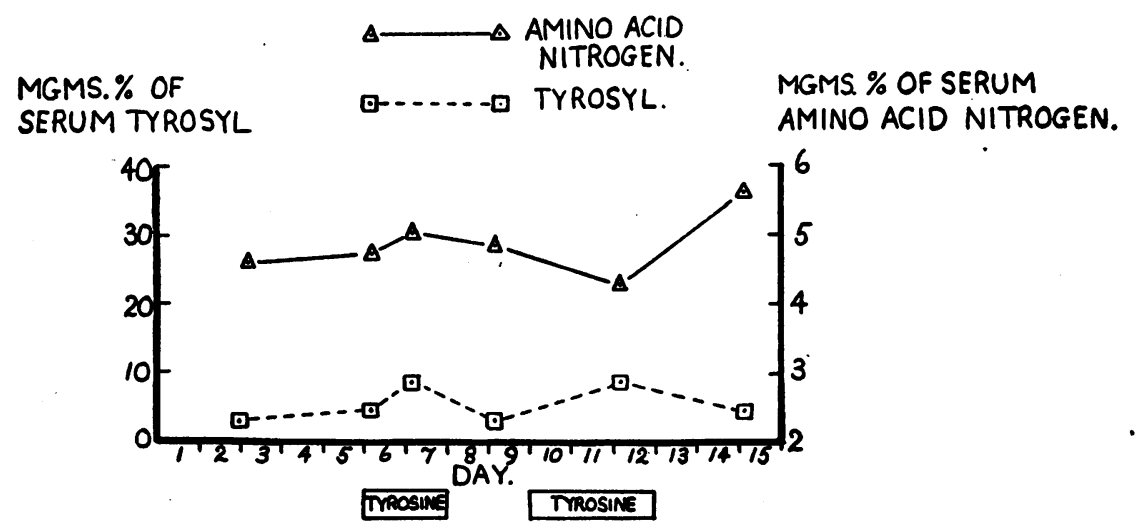

Fre. 48 


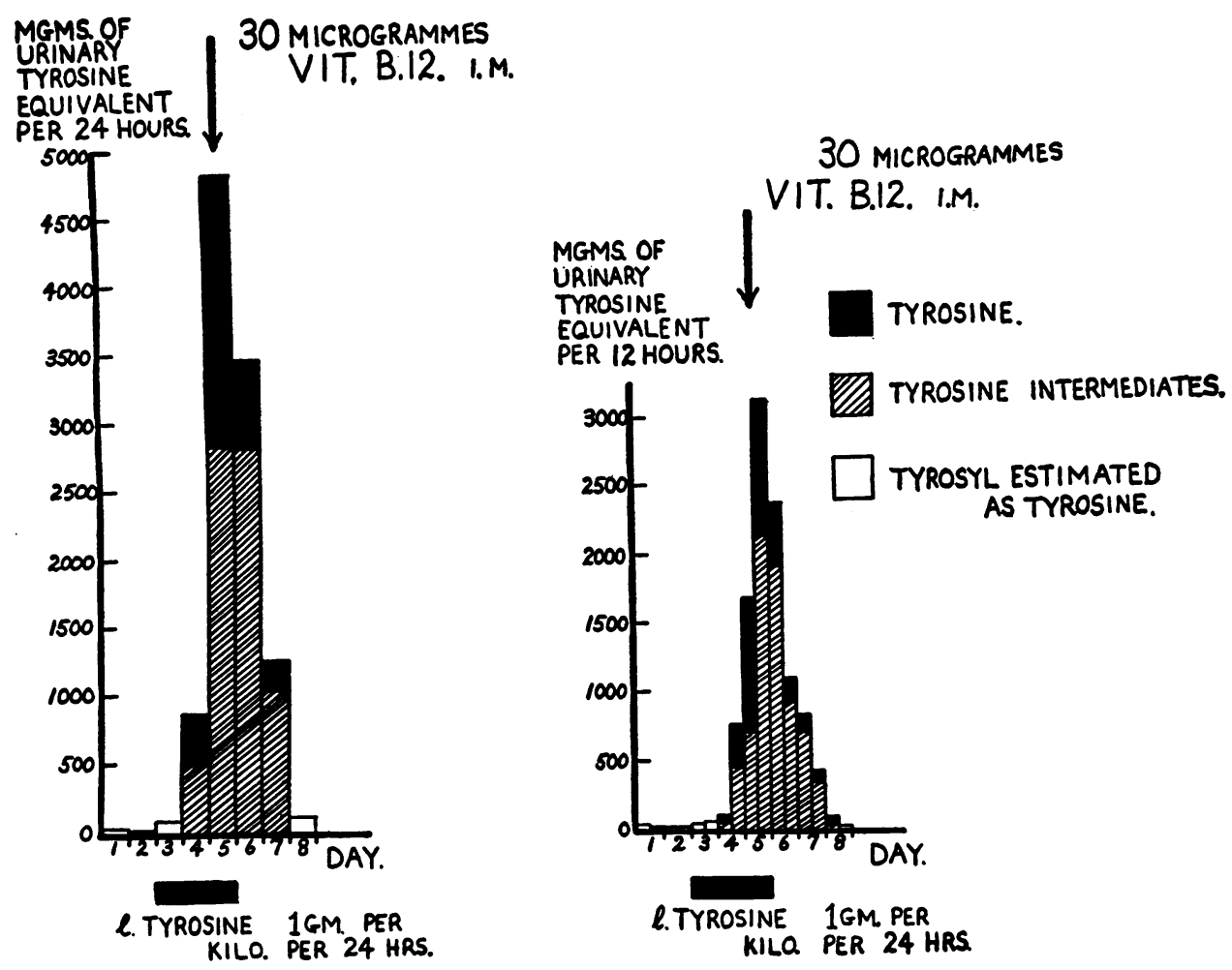

FIG. 5A

change in serum levels was associated with tyrosine feedings.

\section{Case 5. P. P., 7 months. Diagnosis-scurvy}

Figure $5 \mathrm{~A}$ shows both the 12 and 24 hour urinary excretion of tyrosyl when the amino acid was administered for a three day period (periods $3,4,5)$. Although this infant showed severe clinical scurvy associated with considerable edema of the lower extremities and subperiosteal haematomata, it was found that significant tyrosyluria only commenced after 36 hours of tyrosine intake. This was an unexpected finding because it had been assumed that this time lag was a biochemical characteristic of preclinical scurvy. In this state a tissue reserve of ascorbic acid might enable the infant to tolerate the first feedings of tyrosine without manifesting an hydroxyphenyluria.

The injection of 30 microgrammes of vitamin B12 (Rubramin, Squibb) at the midpoint of period 5 during tyrosine ingestion did not prevent a further rise in urinary tyrosyl output during the following 12 hours. Once more, crystals resembling tyrosine were noticed in the urinary sedi- ment at the height of hydroxyphenyluria. Following the termination of tyrosine feeding the uri-

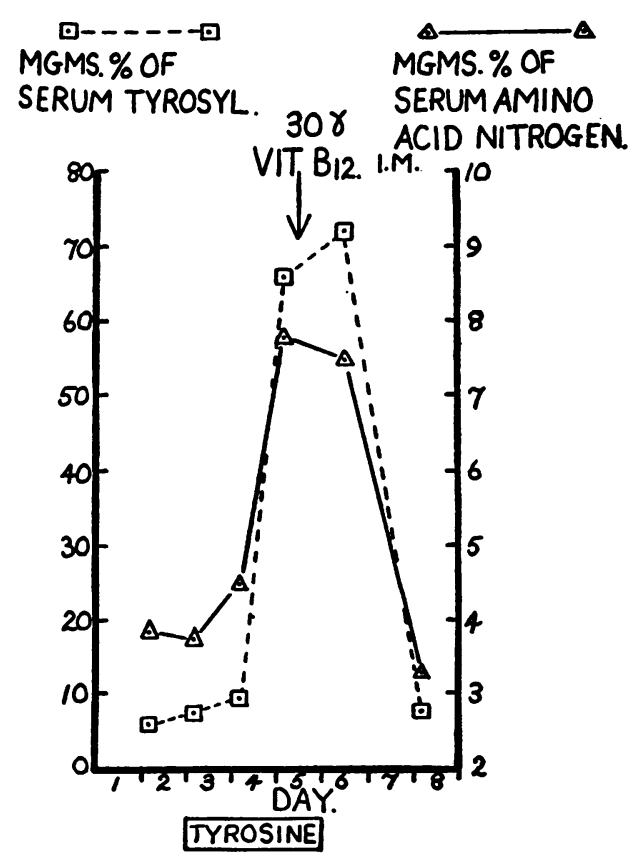

FIG. 5B 

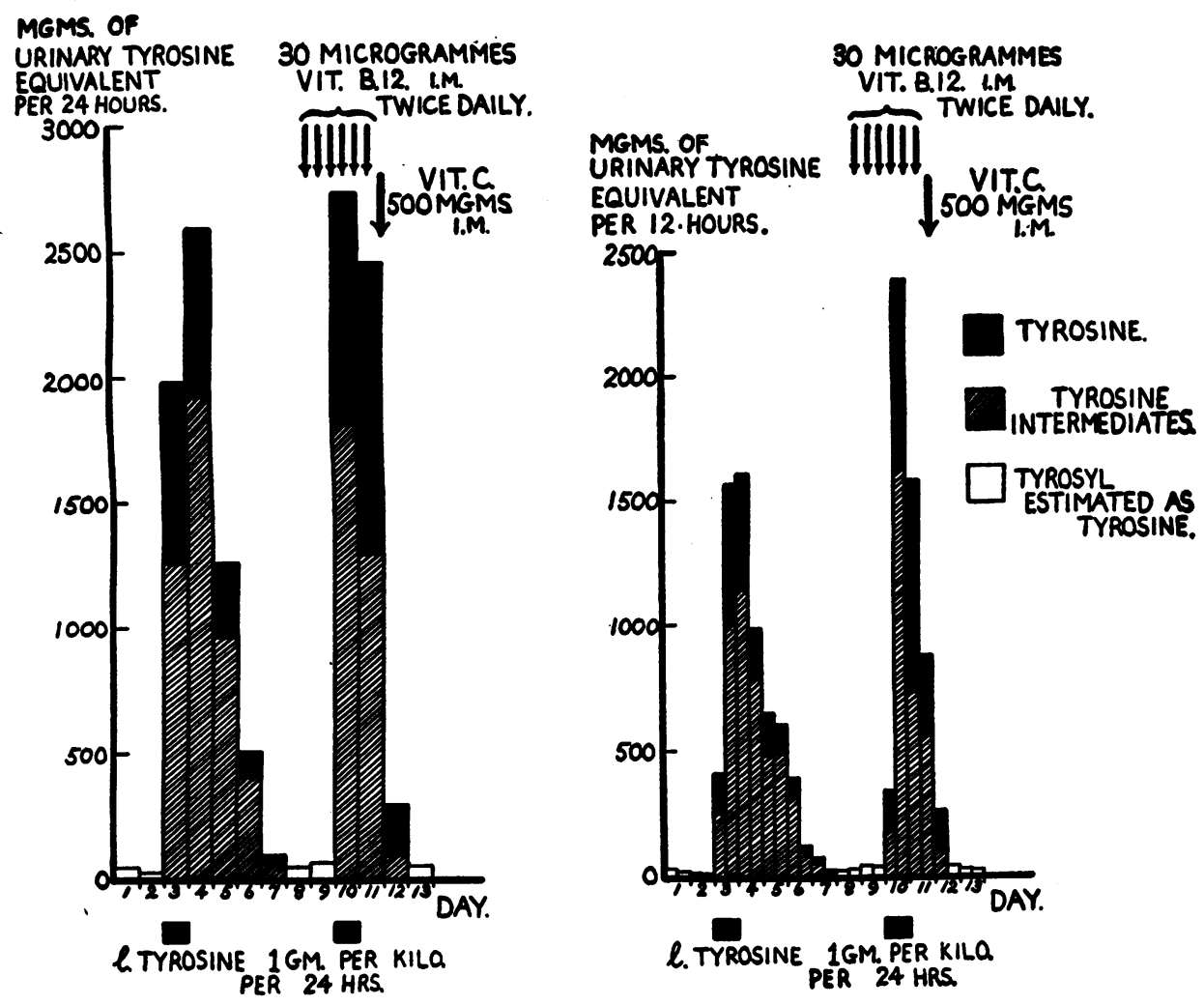

Fig. 6A

nary tyrosyl content gradually subsided to normal values within three days.

Serum samples taken at the periods shown in Figure 5B demonstrated a simultaneous elevation of tyrosyl and amino acid nitrogen levels at the height of hydroxyphenyluria. The injection of vitamin B12 did not influence the serum values.

A deterioration in the clinical condition of the patient did not permit the investigation of the effect of vitamin B12 and tyrosine given concurrently.

Case 6. C. R., 71/2 months. Diagnosis-preclinical scurvy

This infant presented an opportunity to investigate the degree of tyrosyluria when vitamin B12 was given with tyrosine supplements. Figure 6A demonstrates the immediate and intense tyrosyluria evoked by a single day's tyrosine ingestion (period 3). The absence of time lag between feeding and excretion was again surprising because the infant appeared to be healthy and without any scorbutic stigmata.
"Tyrosine" crystals were found in the urine when the tyrosyluria was high. Vitamin B12 in a dosage of 30 microgrammes intramuscularly twice daily was given for three days during periods 9,10 , and 11 with tyrosine feeding during period 10. No specific action could be ascribed to the vitamin since the onset of tyrosyluria was again immediate and crystalluria occurred at the height of excretion. However, when $500 \mathrm{mgms}$. of ascorbic acid were injected intramuscularly, a sharp decline in the hydroxyphenyl output was noted.

Serum estimations (Figure 6B) confirmed the parallelism between tyrosyl and amino acid nitrogen, while vitamin B12 was shown to be ineffective in preventing a rise in these values during the second period of tyrosine ingestion.

This prescorbutic infant therefore demonstrated on two occasions that a single day of tyrosine feeding resulted in an immediate tyrosyluria of considerable magnitude. This hydroxyphenyluria was not influenced by vitamin $\mathrm{B} 12$, in the dosage and manner given, although ascorbic acid was shown to exert a profound effect. 


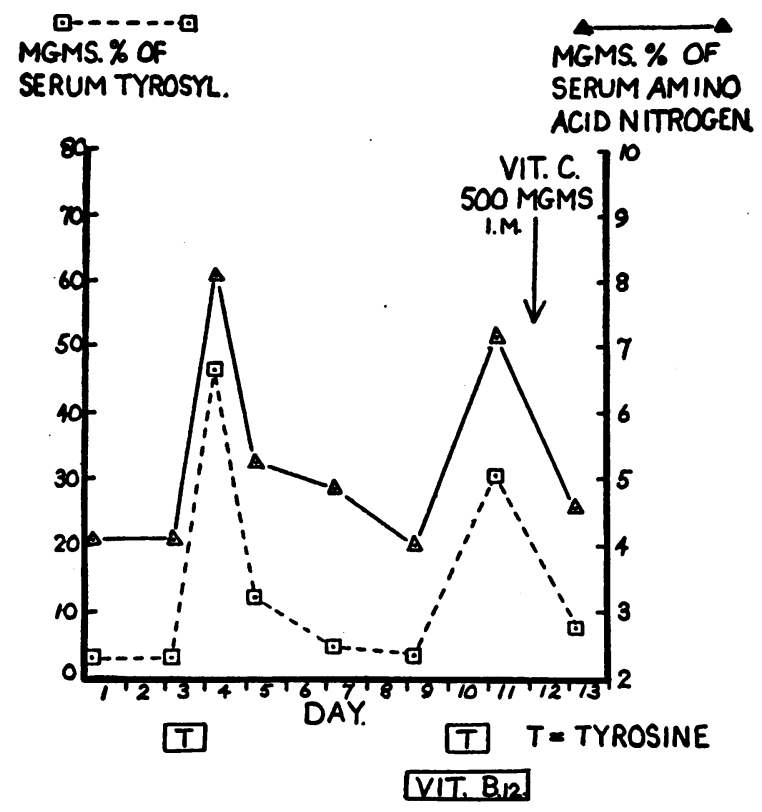

FIG. 6B

\section{DISCUSSION}

This investigation has shown that an increased urinary excretion of tyrosine and its deaminated derivatives follows the ingestion of $l$-tyrosine by vitamin $\mathrm{C}$ depleted human infants. This phenomenon, which is abolished by ascorbic acid, is observed to occur not only in individuals suffering from frank scurvy, but also in those with "preclinical scurvy." The promptness and magnitude of this induced tyrosyluria are not governed by the clinical state of depletion; infants with the same urinary and serum ascorbic acid content respond quite differently to tyrosine consumption. It seems possible, therefore, that the tissues have a variable tenacity for ascorbic acid, and this governs whether the vitamin is made available to participate in the metabolism of tyrosine. However, it is also shown that although PGA failed to influence an established tyrosyluria, a marked inhibition in the hydroxyphenyluria is observed when PGA and tyrosine are given concurrently. This suggests that factors other than the availability of ascorbic acid from the tissues are concerned in the combustion of this aromatic amino acid. The circumstances under which vitamin B12 was investigated in this study demonstrated that it exerted no significant effect on the degree of tyrosyluria.

The significance of these observations with PGA and vitamin $\mathrm{B} 12$ is obscure since it is known that certain liver fractions possess the property to correct partially the incomplete utilization of tyrosine in the premature infant and scorbutic guinea pig $(3,17)$. It is conceivable that this action may be entirely due to the effect of small quantities of PGA contained in such extracts, but it should be remembered that many liver extracts in large doses were found to be ineffective. In addition, the administration of $45 \mathrm{mgms}$. of PGA to one of the infants (Case 2) produced no immediate diminution in hydroxyphenyluria. These facts suggest that some liver fractions contain an agent other than PGA and vitamin B12, which exerts an effect on the metabolism of tyrosine in ascorbic acid depleted individuals.

Because of the many factors implicated in the metabolism of tyrosine, it appears that a tyrosine tolerance test for the diagnosis of ascorbic acid depletion would have a limited usefulness. However, provided that tyrosine ingestion were continued for several days, the analysis of urine for Millon reactors may give a quick confirmation to the clinical impression of ascorbic acid deficiency.

In reviewing the known chemical pathways of tyrosine metabolism, it will be recalled that the aromatic nucleus can either be hydroxylated in the 3,4 positions to DOPA, as in the synthesis of melanin; or the 2, 5 dihydroxy derivatives may be produced, as in alkaptonuria. Alternatively, the side chain of the amino acid molecule may be deaminated to form the corresponding keto and hydroxy acids. These latter compounds are found in the urine of subjects depleted of ascorbic acid during periods of high tyrosine feeding. The knowledge of these three principal pathways is derived either from the inborn errors of metabolism such as phenylketonuria, tyrosinosis, and alkaptonuria, or from an induced metabolic aberration due to vitamin $\mathrm{C}$ depletion. There is no available evidence from which one might assume that these are physiological pathways operating in the normal subject. Furthermore, the observations made in this and other studies of the effect of PGA and ascorbic acid in preventing and abolishing an induced tyrosyluria in the scorbutic state, does not of necessity imply a more complete utilization of tyrosine or phenylalanine. It is possible that these agents are responsible for the rupture of the aromatic nucleus and consequently 
for the production of nonphenolic residues. Painter and Zilva (18) have described experiments with depleted guinea pigs to test the hypothesis that ascorbic acid is implicated in the fission of the benzene ring. They conclude that the dependence of the complete degradation of high doses of $l$ tyrosine on the presence of excess $l$-ascorbic acid does not necessarily indicate a connection between the normal function of that vitamin and the normal metabolism of the aromatic amino acids.

Reference has also been made by Woodruff and associates (5) to the observation that the administration of PGA to scorbutic guinea pigs on a high tyrosine intake will not prevent the development of scurvy although the tyrosyluria is considerably modified. Other authors (19) have pointed out that tyrosine ingestion seems to precipitate and intensify scurvy in the guinea pig maintained on a scorbutogenic diet. It is of interest to note that even in the absence of ascorbic acid administration, the infants studied here were capable of ingesting a formula which supplied 0.3 gm. of aromatic amino acids per kilo per day. without excreting abnormal quantities of urinary hydroxyphenyl compounds. Secondly, although phenylalanine is an essential amino acid, these depleted infants showed no marked stunting of growth or malnutrition which might have resulted if the aromatic amino acids were not utilized. Finally, when tyrosyluria followed tyrosine ingestion it was apparent that a considerable quantity of the consumed tyrosine could not be accounted for by the urinary hydroxyphenyl output. These observations lend support to the hypothesis that other pathways of tyrosine metabolism, not necessarily dependent on ascorbic acid function, are in operation in vitamin $\mathrm{C}$ depleted infants.

The appearance of alkaptonuria on two occasions, when no gross hydroxyphenyluria followed tyrosine ingestion, suggests that the production of homogentisic acid from $l$-tyrosine proceeds in the depleted infant through a pathway which is not influenced by PGA administration. Reference has been made to a similar phenomenon occurring in the depleted guinea pig (5).

The biochemical processes whereby the keto and hydroxy acids, resulting from the deamination of tyrosine, are eliminated in the urine, have received little attention in the literature, but it has been verified that their excretion is associated with a high hydroxyphenyl content of the gut, liver, kidney, muscle and blood, in the scorbutic guinea pig undergoing tyrosine feeding (20). The elevation in serum content of tyrosyl and amino acid nitrogen observed to occur in the scorbutic infant, corroborates the latter observation. However, the site of production of the hydroxy and keto acids remains a mystery. The parallelism between the amino nitrogen and tyrosyl values suggests that the circulating hydroxyphenyl content is solely due to tyrosine. Moreover, it would appear from experiments conducted by other workers (2) that parahydroxyphenylpyruvic acid when given to ascorbic acid depleted guinea pigs is metabolized to a considerable extent, irrespective of the degree of ascorbic acid deficiency. If this situation exists, the role of the kidney in the deamination of tyrosine, whereby parahydroxyphenylpyruvic and parahydroxyphenyllactic acids are produced, would be akin to that occurring in phenylketonuria. In this condition, phenylpyruvic acid is present in the urine although the serum contains no detectable keto or hydroxy acid, but considerable quantities of phenylalanine (21). This problem of the site of deamination of tyrosine in the scorbutic state requires further investigation.

\section{SUMMARY}

1. Six male infants with either scurvy or preclinical scurvy exhibited hydroxyphenyluria of varying degree following tyrosine ingestion. Darkening was observed in the urine of two subjects when the hydroxyphenyl excretion was minimal.

2. Ascorbic acid given intramuscularly produced a marked decrease in the urinary excretion of tyrosyl compounds although tyrosine feeding was continued.

3. Intramuscular PGA given concurrently with tyrosine ingestion inhibited tyrosyluria.

4. Parenteral vitamin B12 failed to influence the urinary excretion of tyrosine derivatives whether given as a single injection during an established hydroxyphenyluria, or concurrently with tyrosine feeding.

5. Serum tyrosyl values were elevated during periods of tyrosyluria.

6. Serum amino nitrogen values paralleled the changes in serum tyrosyl content. 


\section{BIBLIOGRAPHY}

1a. Levine, S. Z., Marples, E., and Gordon, H. H., A defect in the metabolism of tyrosine and phenylalanine in premature infants. I. Identification and assay of intermediary products. J. Clin. Invest., 1941, 20, 199.

b. Levine, S. Z., Gordon, H. H., and Marples, E., A defect in the metabolism of tyrosine and phenylalanine in premature infants. II. Spontaneous occurrence and eradication by vitamin C. Ibid., 1941, 20, 209.

2. Sealock, R. R., Perkinson, J. D., Jr., and Basinski, D. H., Further analysis of the rôle of ascorbic acid in phenylalanine and tyrosine metabolism. J. Biol. Chem., 1941, 140, 153.

3. Sealock, R. R., and Lepow, J. P., Antipernicious anemia extracts and tyrosine metabolism in the scorbutic guinea pig. J. Biol. Chem., 1948, 174, 763.

4. Woodruff, C. W., and Darby, W. J., An in vivo effect of pteroylglutamic acid upon tyrosine metabolism in the scorbutic guinea pig. J. Biol. Chem., 1948, $172,851$.

5. Woodruff, C. W., Cherrington, M. E., Stockell, A. K., and Darby, W. J., The effect of pteroylglutamic acid and related compounds upon tyrosine metabolism in the scorbutic guinea pig. J. Biol. Chem., 1949, 178, 861.

6. Govan, C. D., Jr., and Gordon, H. H., The effect of pteroylglutamic acid on the aromatic amino acid metabolism of premature infants. Science, 1949, 109, 332.

7. Rodney, G., Swendseid, M. E., and Swanson, A. L., The rôle of pteroylglutamic acid in tyrosine oxidation by rat liver tissue. J. Biol. Chem., 1949, 179, 19.

8. Lan, T. H., and Sealock, R. R., Metabolism in vitro of tyrosine by liver and kidney tissues of normal and vitamin C-deficient guinea pigs. J. Biol. Chem., 1944, 155, 483.

9. Sealock, R. R., and Goodland, R. L., The oxidation of $l$-tyrosine by guinea pig liver extracts. J. Biol. Chem., 1949, 178, 939.

10. Abbott, L. de F., Jr., and Salmon, C. L., Jr., Experimental alkaptonuria in the white rat on high tyrosine diets. J. Biol. Chem., 1943, 150, 339.
11. Sealock, R. R., and Silberstein, H. E., The excretion of homogentisic acid and other tyrosine metabolites by the vitamin C-deficient guinea pig. J. Biol. Chem., 1940, 135, 251.

12. Medes, G., A new error of tyrosine metabolism: Tyrosinosis. The intermediary metabolism of tyrosine and phenylalanine. Biochem. J., 1932, 26, 917.

13. Evelyn, K. A., Malloy, H. T., and Rosen, C. The determination of ascorbic acid in urine with the photoelectric colorimeter. J. Biol. Chem., 1938, 126, 645.

14. Mindlin, R. L., and Butler, A. M., Determination of ascorbic acid in plasma; a macromethod and micromethod. J. Biol. Chem., 1938, 122, 673.

15. Gerngross, O., Voss, K., and Herfeld, H., Uber eine hochemphindliche streng tyrosinspezifische Farbreaktion auf para-substituierte Phenole. Der Tyrosin-Gerhalt verschiedener Proteine, insbesondere von Kollagen und Gelatine. Ber. deutsch. Chem. Gesellsch., 1933, 66, 435.

16. Krauel, K. K., Microdetermination of amino acid nitrogen in blood with spectrophotometer and with optical colorimeter. J. Lab. \& Clin. Med., 1944, 29, 222.

17. Levine, S. Z., Tyrosine and phenylalanine metabolism in infants and the role of vitamin C. Harvey Lectures, 1946-47, 4, 303.

18. Painter, H. A., and Zilva, S. S., The influence of $l$ ascorbic acid on the rupture of the benzene ring of l-tyrosine consumed in high doses by guinea-pigs. Biochem. J., 1947, 41, 511.

19. Clegg, R. E., and Sealock, R. R., The metabolism of dihydroxyphenylalanine by guinea pig kidney extracts. J. Biol. Chem., 1949, 179, 1037.

20. Painter, H. A., and Zilva, S. S., The influence of bactericidal agents and of the absence of $l$-ascorbic acid on the accumulation of hydroxyphenyl compounds in the large intestine of guinea pigs after the consumption of high doses of $l$-tyrosine. Biochem. J., 1948, 43, 398.

21. Jervis, G. A., Block, R. J., Bolling, D., and Kanze, E., Chemical and metabolic studies on phenylalanine. II. The phenylalanine content of the blood and spinal fluid in phenylpyruvic oligophrenia. J. Biol. Chem., 1940, 134, 105. 